\title{
Corrigendum to "Validity and Reliability of Farsi Version of Youth Sport Environment Questionnaire"
}

\author{
Mohammad Ali Eshghi, ${ }^{1}$ Ramin Kordi, ${ }^{2}$ Amir Hossein Memari, ${ }^{2}$ Ahmad Ghaziasgar, \\ Mohammad-Ali Mansournia, ${ }^{3}$ and Seyed Hojjat Zamani Sani ${ }^{4}$ \\ ${ }^{1}$ Exercise Physiology Research Center, Baqiyatallah University of Medical Sciences, Tehran, Iran \\ ${ }^{2}$ Sports Medicine Research Center, Tehran University of Medical Sciences, P.O. Box 14395-578, Tehran, Iran \\ ${ }^{3}$ Department of Epidemiology and Biostatistics, School of Public Health, Tehran University of Medical Sciences, Tehran, Iran \\ ${ }^{4}$ Faculty of Physical Education and Sport Sciences, University of Tabriz, Tabriz, Iran
}

Correspondence should be addressed to Amir Hossein Memari; amirmemari@farabi.tums.ac.ir

Received 28 September 2015; Accepted 1 October 2015

Copyright (C) 2015 Mohammad Ali Eshghi et al. This is an open access article distributed under the Creative Commons Attribution License, which permits unrestricted use, distribution, and reproduction in any medium, provided the original work is properly cited.

In the paper entitled "Validity and Reliability of Farsi Version of Youth Sport Environment Questionnaire," [1] there was an error in the 4th institutional affiliation and it is corrected above.

\section{References}

[1] M. A. Eshghi, R. Kordi, A. H. Memari, A. Ghaziasgar, M. Mansournia, and S. H. Zamani Sani, "Validity and reliability of farsi version of youth sport environment questionnaire," Journal of Sports Medicine, vol. 2015, Article ID 985283, 5 pages, 2015. 


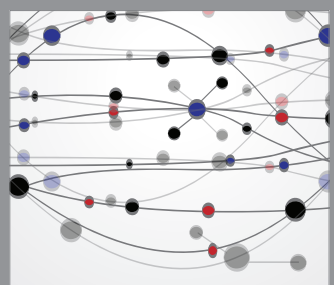

The Scientific World Journal
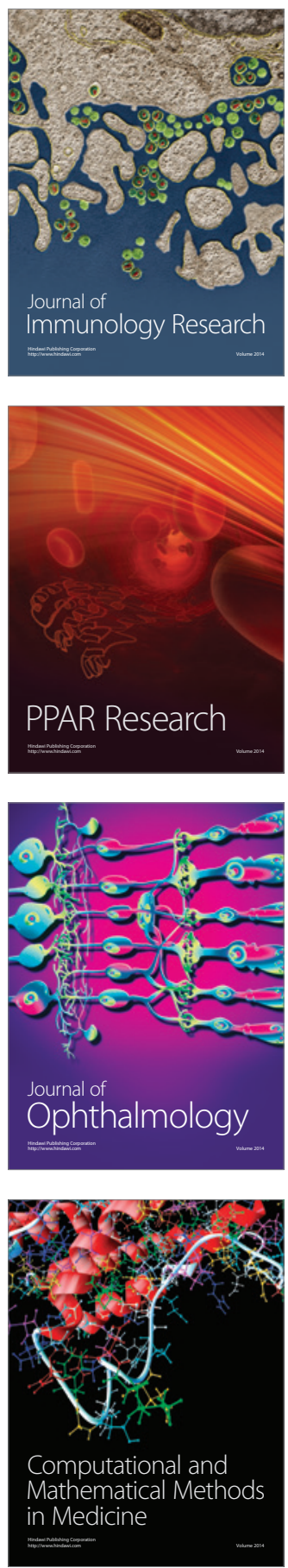

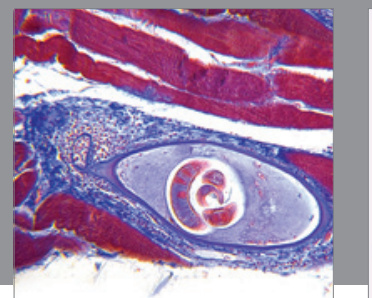

Gastroenterology

Research and Practice
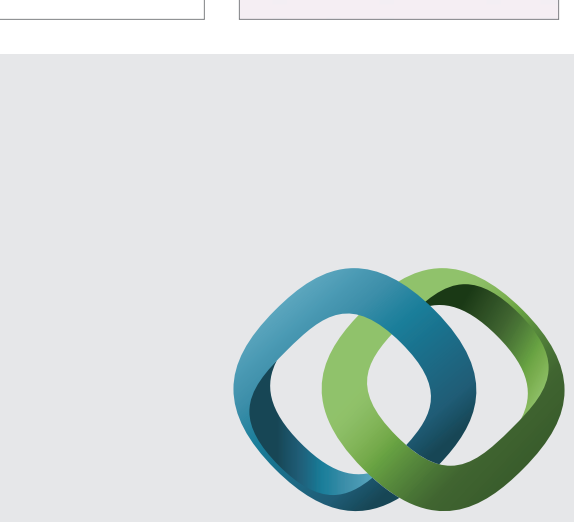

\section{Hindawi}

Submit your manuscripts at

http://www.hindawi.com
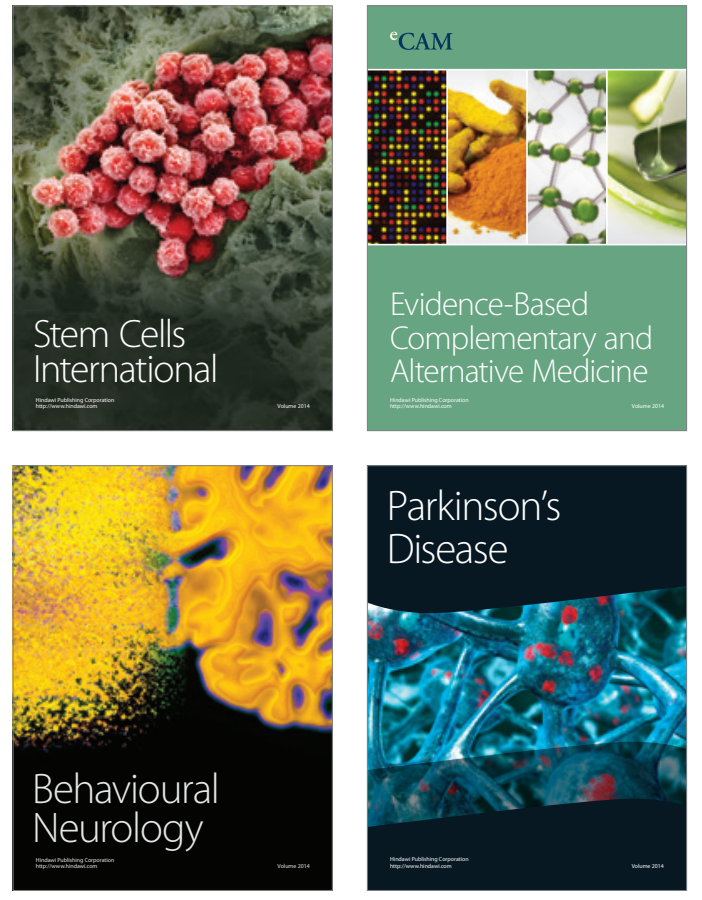
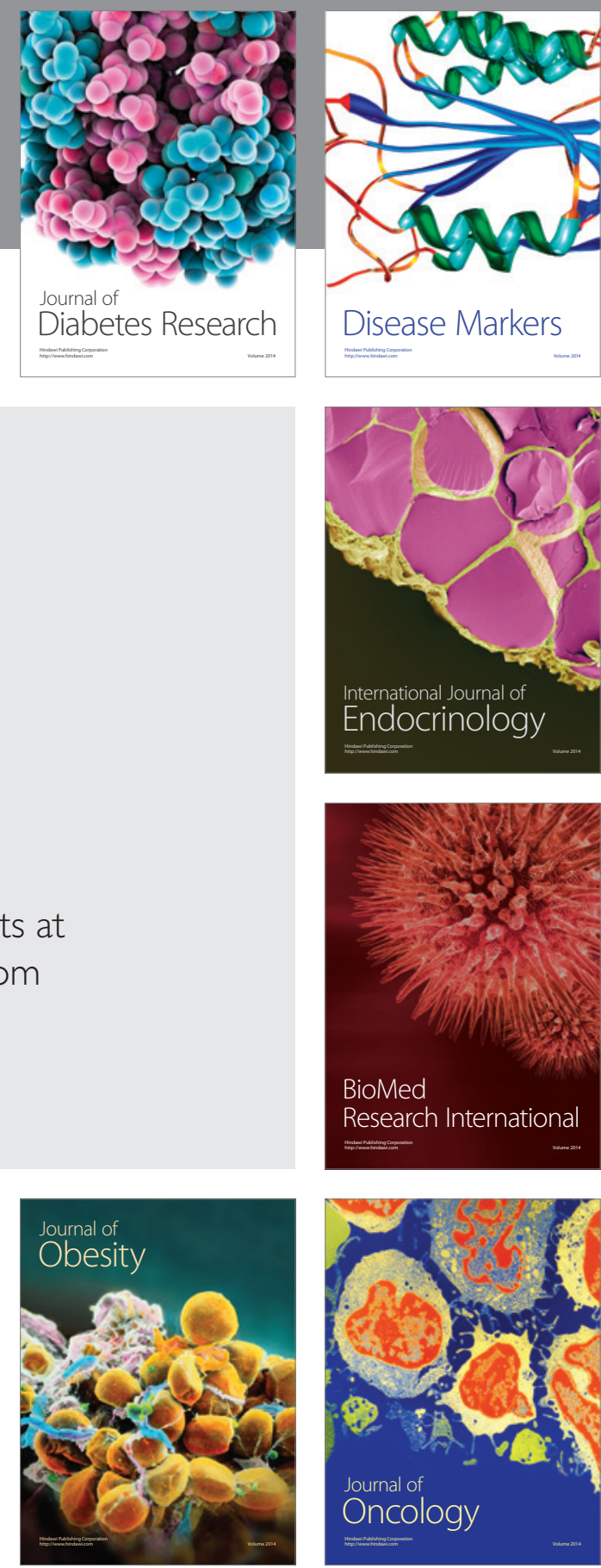

Disease Markers
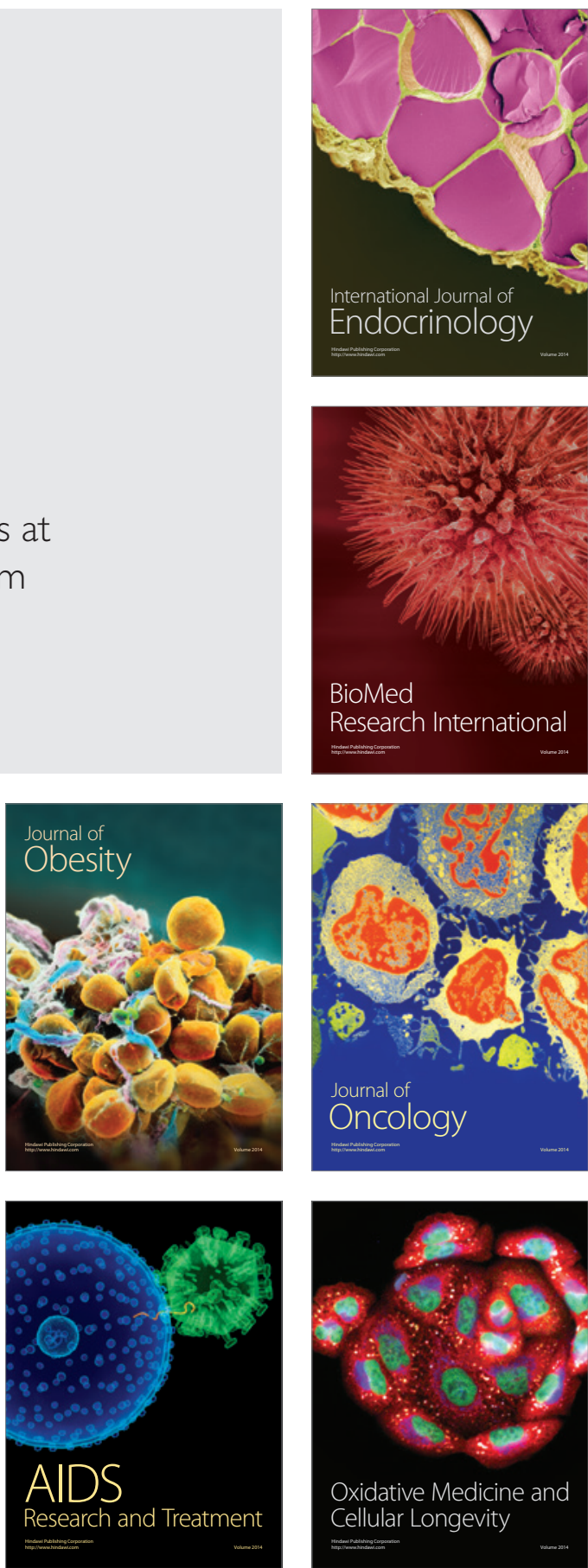